\title{
Plasma renin activity and aldosterone concentration in the human newborn
}

\author{
M. J. DILLON, MARY E. A. GILLIN, JENNIFER M. RYNESS, and M. de SWIET \\ From the Institute of Child Health, and Queen Charlotte's Maternity Hospital, London
}

\begin{abstract}
Dillon, M. J., Gillin, M. E. A., Ryness, J. M., and de Swiet, M. (1976). Archives of Disease in Childhood, 51, 537. Plasma renin activity and aldosterone concentration in the human newborn. Twenty-one healthy newborn infants whose mothers had normal pregnancies and deliveries were studied. Plasma renin activity (PRA) and plasma aldosterone concentration (PAldo) were measured by semimicro methods in cord blood and on the 6th day of life. PRA and PAldo were increased in cord blood compared with values previously found in healthy infants between 1 month and 1 year of age. There was a twofold reduction in both values by the 6th day. PRA and PAldo were positively correlated when cord blood and 6th-day values were considered as a whole, but no significant correlations were found between either cord blood PRA or cord blood PAldo and their respective values on the 6th day. The PRA and PAldo findings were not related to birthweight, the infant's sex, weight change, 6th-day urinary sodium, or blood pressure measurements. The type of milk feed did not influence PRA but PAldo was slightly greater in bottlefed babies on the 6th day.

These observations confirm that the inverse relationship between PRA, PAldo, and age extends into the neonatal period but they suggest that the balance of factors controlling these variables at birth is different to that operating at the age of 6 days.
\end{abstract}

Animal studies have shown increased activity of the renin-angiotensin-aldosterone system in the newborn of various species (Pipkin, Mott, and Roberton, 1971; Granger et al., 1971; Malinowska and Nathanielsz, 1974; Pipkin et al., 1974). Only limited data are available on human newborns, but increased plasma renin activity (PRA) and raised plasma renin (PRC), and angiotensin II (PAII) concentrations have been reported (Kotchen et al., 1972; Hayduk et al., 1972; Pipkin and Smales, 1975). Raised plasma aldosterone concentrations (PAldo) have also been found (Beitins et al., 1972; Siegel, Fisher, and Oh, 1974; Katz, Beck, and Makowski, 1974).

In these earlier studies, however, conditions of sampling were not always strictly controlled and with one exception (Katz et al., 1974) they reported either the plasma renin or the plasma aldosterone level. Since the renin-angiotensin system plays an essential part in the control of aldosterone secretion we thought it important to explore this relationship further in the newborn. The development of

Received 5 November 1975. semimicro techniques has enabled us to measure PRA and PAldo concurrently under controlled conditions in healthy newborn infants and relate these values to sodium excretion and blood pressure measurements.

\section{Subjects and methods}

We studied 21 healthy newborn infants whose mothers had had normal pregnancies and deliveries. Cord venous blood samples $(1.5 \mathrm{ml})$ were taken at the time of birth into tubes containing disodium EDTA $(5.5 \mathrm{mg} / \mathrm{ml})$. They were maintained at $4^{\circ} \mathrm{C}$ until centrifuged and the separated plasma was then stored at $-20^{\circ} \mathrm{C}$ until assayed. A second blood sample was taken by venepuncture at $10 \mathrm{a} . \mathrm{m}$. on the 6th day of life. Part of this specimen was used for the Guthrie test and the remainder was prepared for analysis in the same way as the cord blood sample. The 6th-day sample was taken 3 hours after feeding and the baby kept supine for 1-2 hours before the sample was taken. The babies were fed as their mothers wished. Six babies $(29 \%)$ were bottle-fed (Cow \& Gate, Baby Milk Plus) and the remainder breast fed. A random urine sample was collected for sodium and creatinine estimations on the morning of the 6th day. Before the second blood sample was taken systolic blood pressure was recorded in the 
right upper limb by the Parkes Doppler ultrasound system (Elseed, Shinebourne, and Joseph, 1973) with a 4-cm cuff and conventional sphygmomanometer. The study was approved by the Ethical Committee of Queen Charlotte's Maternity Hospital and the mother's permission for the 6th-day venepuncture and urine sample was obtained.

PRA was measured on $0.25 \mathrm{ml}$ plasma by the radioimmunoassay of generated angiotensin I (AI) (Dillon, 1975) and expressed as pmol $\mathrm{AI} \mathrm{ml} \mathrm{ml}^{-1} \mathrm{~h}^{-1}$. PAldo was also measured by radioimmunoassay on $0.5 \mathrm{ml}$ plasma using a modification (Dillon and Ryness, 1975) of the method of Mayes et al. (1970) and expressed as pmol/1. Urine sodium concentration was measured by flame photometry and creatinine by the Jaffe reaction on an AutoAnalyser. From the sodium/creatinine concentration ratio the infant's daily sodium/excretion ( $\mathrm{UNa}$ ) was calculated assuming a constant daily creatinine excretion. The differences between mean values were assessed by Student's paired and unpaired ' $t$ ' tests as appropriate on logarithmically transformed data.

\section{Results}

PRA fell significantly ( $P<0.0025)$ from a mean of $2.86 \mathrm{pmol} \mathrm{AI} \mathrm{m} \mathrm{m}^{-1} \mathrm{~h}^{-1}(3709 \mathrm{ng} / 1$ per $\mathrm{h}$ ) in venous cord blood at birth to a mean of $1 \cdot 18 \mathrm{pmol}$ AI $\mathrm{ml}^{-1} \mathrm{~h}^{-1}$ (1530 ng/1 per $\mathrm{h}$ ) on the 6th day (Fig. 1). The latter value was not significantly different from the mean value for healthy infants under one year

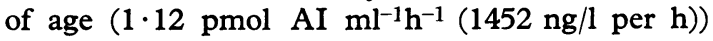
(Dillon and Ryness, 1975).

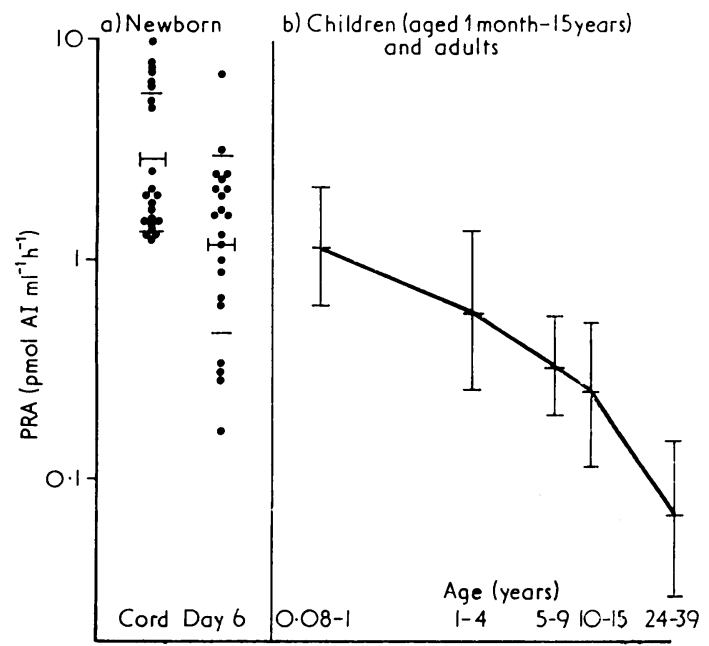

FIG. 1.-(a) PRA (pmol $A I \mathrm{ml}^{-1} h^{-1}$ ) in cord blood and on 6th day. Geometric means $\pm 1 S D$ shown by horizontal lines. (b) Relation between PRA and age in normal supine subjects. Geometric means shown by horizontal lines: vertical bars represent $\pm 1 S D$ (Dillon and Ryness, 1975). Conversion: $S I$ to traditional units-Angiotensin: $1 \mathrm{pmol} / \mathrm{ml} \approx 1297 \mathrm{ng} / \mathrm{l}$.
PAldo also fell significantly $(P<0.005)$ from a mean of $2268 \mathrm{pmol} / 1(81 \cdot 14 \mathrm{ng} / 100 \mathrm{ml})$ in venous cord blood at birth to a mean of $1248 \mathrm{pmol} / 1$ $(45.05 \mathrm{ng} / 100 \mathrm{ml}$ ) on the 6 th day (Fig. 2). The latter value was significantly greater $(P<0.05)$ than the previously reported mean value for healthy infants under one year of age (780 pmol/1 (28.40 $\mathrm{mg} / 100 \mathrm{ml})$ ) (Dillon and Ryness, 1975).

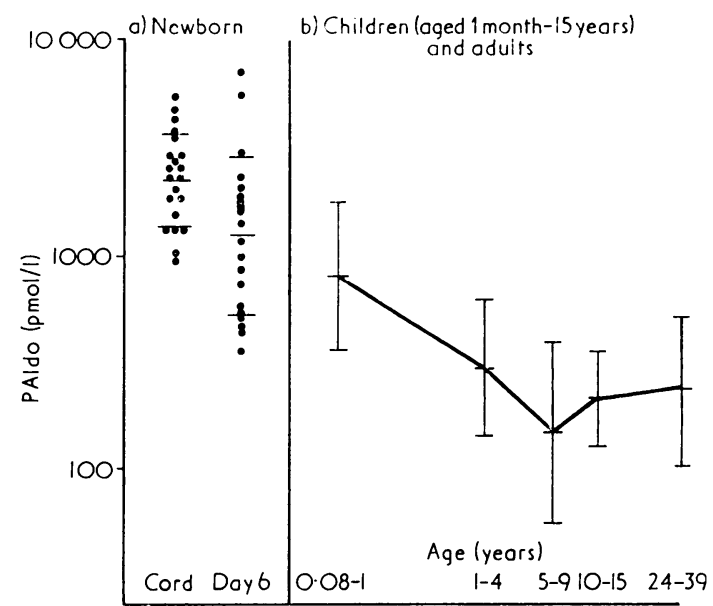

FIG. 2.-(a) PAldo in cord blood and on 6th day. Geometric means $\pm 1 S D$ shown by horizontal lines. (b) Relation between PAldo and age in normal supine subjects. Geometric means shown by horizontal lines; vertical bars represent $\pm 1 S D$ (Dillon and Ryness, 1975). Conversion: SI to traditional units-Aldosterone: $1 \mathrm{pmol} / \mathrm{l} \approx$ $0.036 \mathrm{ng} / 100 \mathrm{ml}$.

PRA and PAldo were significantly and positively correlated $(P<0.05)$ when cord blood and 6th-day values were considered as a whole. Neither PRA nor PAldo in cord blood were significantly correlated with their respective values on the 6th day. In addition, there were no significant correlations shown between cord blood or 6th-day values of PRA and PAldo and birthweight, the sex of the infant, weight change between birth and the 6th day, urinary sodium excretion, or blood pressure on the 6th day.

There were no significant differences in PRA between breast- and bottle-fed infants at birth or on the 6th day. However, mean PAldo was just significantly greater in the artificially fed babies on the 6th day $(2040 \mathrm{pmol} / 1(73 \cdot 44 \mathrm{ng} / 100 \mathrm{ml}))$ than in those breast-fed (1012 pmol/1 $(36 \cdot 43 \mathrm{ng} / 100$ $\mathrm{ml}))(P<0 \cdot 05)$, although there were no differences between the mean values in cord blood. 


\section{Discussion}

The results of this study clearly showed increased activity of the renin-aldosterone system in the healthy newborn infant. Our findings of increased PRA and PAldo in venous cord blood agree with those of others. Kotchen et al. (1972) and Katz et al. (1974) found increased cord blood PRA, Hayduk et al. (1972) increased PRC, and Pipkin and Smales (1975) increased PAII. Similarly raised values of PAldo in cord blood have been reported (Beitins et al., 1972; Katz et al., 1974). However, there is conflicting data on plasma renin and aldosterone levels during the subsequent neonatal period. Kotchen et al. (1972) found that PRA increased between 3 and 6 days of life and subsequently declined. Hayduk et al. (1972) reported a rise in PRC between 3 and 48 hours of life, decreasing to below cord blood values by 3 to 10 days, and Pipkin and Smales (1975) found that PAII decreased by almost two-thirds during the first 6 days of life. Our findings are not incompatible with these reports since the early rise in PRA and PRC respectively reported by Kotchen et al. (1972) and Hayduck et al. (1972) would not have been detected in our study. On the other hand, our PAldo data on the 6th day of life contrast with the limited information in the literature. Beitins et al. (1972) and Kowarski, Katz, and Migeon (1974) found that, although raised, PAldo remained unchanged during the first 3 days of life. Siegel et al. (1974) measured PAldo only between 24 and 48 hours of life and found these values increased. In addition, it has also been reported that between 1 week and 1 year of life PAldo levels increase dramatically compared with those of the first 3 days (Kowarski et al., 1974). Our findings of a twofold reduction between cord blood and 6th-day PAldo is at variance with some of the above reports but parallels our PRA data.

Our data also confirm that the inverse relationship we have previously shown between PRA, PAldo, and age in children (Dillon and Ryness, 1975) extends into the neonatal period (Figs. 1 and 2). We cannot account for the higher PAldo levels observed in bottle-fed babies, but the difference was so marginally significant that we would not wish to emphasize it. It seems unlikely to be due to differences in sodium intake since the sodium content of breast milk and Cow \& Gate Baby Milk Plus are similar, and a casual urine specimen suggested that there were no significant differences in sodium excretion.

The lack of correlation between PRA or PAldo with the 6th-day blood pressure does not surprise us in view of the marked blood pressure variability observed in the neonatal period (de Swiet, Fancourt, and Peto, 1975).

The cause of the increased values of PRA and PAldo in the neonatal period is not clear. In normal children from infancy to adolescence PRA and PAldo levels are almost entirely dependent on age and only marginally attributable to differences in sodium intake (Dillon and Ryness, 1975). Our newborn data seem to confirm this. However, it is interesting that although mean cord blood renin and aldosterone values were significantly higher than the 6th-day values, in individual babies there was no correlation between cord blood and 6th-day levels. This suggests that the balance of factors controlling PRA and PAldo at birth is different to that operating at the age of six days. The stress of vaginal delivery may be an important factor. Beitins et al. (1972) showed that cord blood PAldo was higher in vaginally-delivered babies compared with those delivered by elective caesarean section. This is supported by animal work in which lambs delivered by caesarean section had significantly lower concentrations of PAII than those delivered vaginally (Pipkin et al., 1974). The same workers have also shown in a chronically catheterized fetal lamb that a significant rise in PRC occurred after vaginal delivery (Pipkin et al., 1974). We have also observed that in a limited number of babies born by casarean section the PRA values in cord blood were lower than those found in vaginally delivered infants although PAldo values were of the same order (Dillon et al., unpublished).

The factors that stimulate renin release during parturition are not well understood. Hypoxaemia is unlikely to be responsible but blood loss and/or falls, or both, of fetal arterial pressure during uterine contractions may be important (Mott, 1975). The physiological characteristics of the infant kidney may be relevant in the postnatal period. It is well known that renal cortical perfusion is relatively less in the young kidney owing to increased vascular resistance (Gruskin, Edelmann, and Yuan, 1970) and that proximal tubular function is relatively less efficient (Edelmann and Spitzer, 1969). Perhaps the infant and young child is thus more dependent on renin-aldosterone-stimulated distal tubular sodium reabsorption for the maintenance of salt balance (Dillon, 1974).

We acknowledge that we undertook a comparatively limited study and that other interesting measures of renal and adrenal function were unfortunately excluded. As a result of miniaturization of our immunoassay techniques our plasma sample size was extremely small, but ethical con- 
siderations still prevented us from taking larger quantities of blood from healthy babies. However, if increased activity of the renin-angiotensinaldosterone system favours the establishment of postnatal existence it is clearly important that this system be further evaluated in the fetus and newborn.

We thank Professor Barbara E. Clayton for her support and encouragement, Mrs. V. Shah for skilled technical assistance, the midwives and nursing staff of Queen Charlotte's Maternity Hospital for collecting blood and urine specimens, and the obstetricians and paediatricians of Queen Charlotte's Maternity Hospital for permission to study newborns under their care.

M.J.D. holds the Alan Moncrieff Educational Research Fellowship supported by the Buttle Trust. Additional financial support was provided by the Joint Research Board of the Hospital for Sick Children and the Institute of Child Health, London. M. de S. is supported by a grant from the Medical Research Council.

\section{REFERENCES}

Beitins, I. Z., Bayard, F., Levitsky, L., Ances, I. G., Kowarski, A., and Migeon, C. J. (1972). Plasma aldosterone concentration at delivery and during the newborn period. Fournal of Clinical Investigation, 51, 386.

de Swiet, M., Fancourt, R., and Peto, J. (1975). Systolic blood pressure variation in the first 6 days of life. Clinical Science and Molecular Medicine, 49, 557.

Dillon, M. J. (1974). Renin and hypertension in childhood. Archives of Disease in Childhood, $49,831$.

Dillon, M. J. (1975). Measurement of plasma renin activity by semi-micro radioimmunoassay of generated angiotensin $I$. Fournal of Clinical Pathology, 28, 625.

Dillon, M. J., and Ryness, J. M. (1975). Plasma renin activity and aldosterone concentration in children. British Medical fournal, 4, 316.

Edelmann, C. M., Jr., and Spitzer, A. (1969). The maturing kidney. A modern view of well-balanced infants with imbalanced nephrons. Fournal of Pediatrics, 75, 509.
Elseed, A. M., Shinebourne, E. A., and Joseph, M. C. (1973). Assessment of techniques for measurement of blood pressure in infants and children. Archives of Disease in Childhood, $\mathbf{4 8}$ 932.

Granger, P., Rojo-Ortega, J. M., Casado Pérez, S., Boucher, R., and Genest, J. (1971). The renin-angiotensin system in newborn dogs. Canadian fournal of Physiology and Pharmacology, 49, 134.

Gruskin, A. B., Edelmann, C. M., Jr., and Yuan, S. (1970). Maturational changes in renal blood flow in piglets. Pediatric Research, $4,7$.

Hayduk, K., Krause, D. K., Huenges, R., and Unbehaun, V. (1972) Plasma renin concentration at delivery and during the newborn period in humans. Experimentia, 28, 1489.

Katz, F. H., Beck, P., and Makowski, E. L. (1974). The reninaldosterone system in mother and fetus at term. American fournal of Obstetrics and Gynecology, 118, 51 .

Kotchen, T. A., Strickland, A. L., Rice, T. W., and Walters, D. R. (1972). A study of the renin-angiotensin system in newborn infants. Fournal of Pediatrics, 80, 938.

Kowarski, A., Katz, H., and Migeon, C. J. (1974). Plasma aldosterone concentration in normal subjects from infancy to adulthood. Fournal of Clinical Endocrinology and Metabolism, 38, 489.

Malinowska, K. W., and Nathanielsz., P. W. (1974). Plasma aldosterone, cortisol and corticosterone concentrations in the new-born guinea-pig. Fournal of Physiology, 236, 83.

Mayes, D., Furuyama, S., Kem, D. C., and Nugent, C. A. (1970). A radioimmunoassay for plasma aldosterone. fournal of Clinical Endocrinology and Metabolism, 30, 682.

Mott, J. C. (1975). The place of the renin-angiotensin system before and after birth. British Medical Bulletin, 31, 44.

Pipkin, F. B., and Smales, O. R. C. (1975). Blood pressure and angiotensin II in the newborn. Archives of Disease in Childhood, $50,330$.

Pipkin, F. B., Mott, J. C., and Roberton, N. R. C. (1971). Angiotensin II-like activity in circulating arterial blood in immature and adult rabbits. Fournal of Physiology, 218, 385.

Pipkin, F. B., Kirkpatrick, S. M. L., Lumbers, E. R., and Mott, J. C. (1974). Renin and angiotensin-like levels in foetal, newborn and adult sheep. Fournal of Physiology, 241, 575.

Siegel, S. R., Fisher, D. A., and Oh, W. (1974). Serum aldosterone concentrations related to sodium balance in the newborn infant. Pediatrics, 53, 410.

Correspondence to Dr. M. J. Dillon, Institute of Child Health, 30 Guilford St., London WC1N 1EH. 